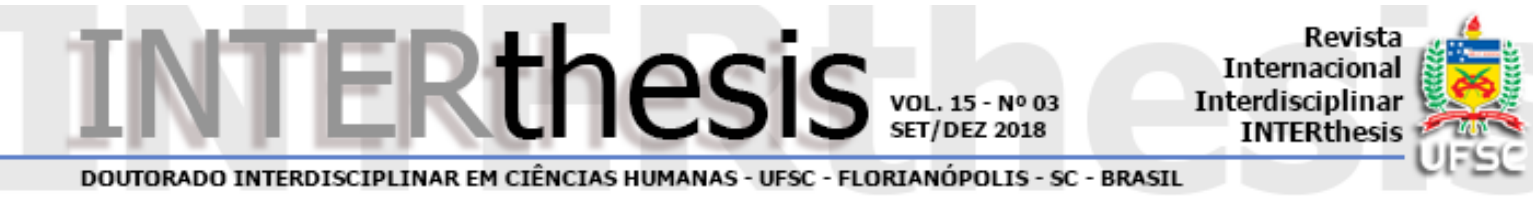

\title{
O BAILARINO E SEU CONTEXTO PROFISSIONAL: UM ESTUDO ACERCA DA IDENTIDADE PROFISSIONAL ${ }^{1}$
}

\section{Resumo:}

Ana Ligia Trindade e Patricia ${ }^{2}$ Kayser Vargas Mangan ${ }^{3}$

A proposta deste estudo na área da Memória Social tem como objetivo discutir acerca de conceitos de identidade, profissão e arte como trabalho, tendo como ênfase o profissional bailarino. O termo identidade não pode ser compreendido senão por vias interdisciplinares, no entrecruzamento de áreas como a Sociologia, a Psicologia, a Antropologia e a História. Nesse contexto, se compreende identidade profissional como um processo contínuo que se vincula à identidade pessoal, igualmente ligada aos vínculos e sentimentos de pertencimento a uma determinada categoria ou grupo social. As considerações levantadas, acerca de identidade, profissão, ofício, ocupação e trabalho, têm a finalidade de contextualização para o estudo que está tentando delinear uma imagem e identidade do profissional bailarino, bem como instigar novas pesquisas nesta temática.

Palavras-chaves: Identidade. Profissional Bailarino. Dança.

\section{INTRODUÇÃO}

Para cada um de nós a identidade expressa a representação que temos de nós mesmos. Deste modo, as identidades são representações subjetivas que se constroem a partir de diferentes discursos e práticas sociais (HALL, 2006). A pesquisa em andamento do qual emerge este trabalho está em busca da compreensão da identidade profissional do bailarino no Estado do Rio Grande do Sul, na qual também surgem questionamentos sobre profissão, ofício, ocupação e trabalho; além da necessidade de investigar as artes como profissão. O estudo aqui apresentado foi realizado considerando o contexto nacional, levando-se em conta o

\footnotetext{
1 O trabalho está sendo realizado com apoio da Coordenação de Aperfeiçoamento de Pessoal de Nível Superior - Brasil (CAPES) - Código de Financiamento 001 "This study was financed in part by the Coordenação de Aperfeiçoamento de Pessoal de Nível Superior - Brasil (CAPES) - Finance Code 001.

2 Doutoranda em Memória Social e Bens Culturais pelo Centro Universitário da Universidade Luterana do Brasil, Canoas, RS. Bailarina, coreógrafa e professora de Ballet. E-mail: ligia-trindade@bol.com.br ${ }_{3}^{3}$ Doutora em Engenharia de Sistemas e Computação pela Universidade Federal do Rio de Janeiro. Professora da Universidade Luterana do Brasil, Canoas, RS vinculada ao Mestrado Profissional em Memória Social e Bens Culturais na mesma universidade. E-mail: patricia.kayser@gmail.com
} 
profissional formal e independente, sem restringir a um estilo específico, buscando um diagnóstico geral da situação deste profissional no país.

Em diferentes períodos e espaços atribuímos significados às nossas experiências e aquilo que somos como profissionais, significando dizer que a construção da identidade profissional é "um território de disputa permanente" (LIMA, 2012). A tentativa de delinear uma identidade profissional do bailarino pressupõe situá-lo na complexidade de um contexto social, histórico, político e cultural. Uma contextualização contemporânea de profundas mudanças que estão provocando transformações na profissão e no próprio bailarino, uma vez que a constituição de identidade tem relação com a realidade na qual se insere. Nesse sentido alguns pontos afetam a maneira como exercemos a profissão e possíveis discussões se apresentam implicando em novos princípios estruturadores de nossa identidade profissional.

Assim, a proposta deste estudo discute o conceito de identidade na área da Memória Social tendo como objetivo fundamentar acerca de conceitos de identidade, profissão e arte como trabalho, dando ênfase ao profissional bailarino.

\section{MEMÓRIA E IDENTIDADE}

Halbwachs ao apresentar o conceito de quadros sociais da memória, afirma que "não há memória possível fora dos quadros dos quais os homens, vivendo em sociedade, se servem para fixar e reencontrar suas lembranças" $(1925,1994$, p.79). Esses quadros integram, eles mesmos, antigas lembranças que vão orientar a construção de novas. Ou seja, funcionam como pontos de referência para a construção subjetiva de lembranças e determinam o que deve ser lembrado, esquecido, silenciado ou comemorado pelos indivíduos. Esta contextualização inclui também a padronização social do tempo e do espaço, dimensões, segundo Halbwachs, fundamentais da experiência humana. A padronização do tempo e do espaço permite a formação de memórias, que cumprem uma função social fundamental: elas contribuem para a manutenção e coesão dos grupos, na medida em que ajudam a produzir o sentimento de identidade entre seus membros (RIOS, 2013).

Ainda para Halbwachs (2006), a memória individual existe sempre a partir de uma memória coletiva. Ele apresenta uma metáfora emblemática do modelo de 
sociedade: a imagem da orquestra em que os músicos são capazes de se harmonizar para executar uma mesma sinfonia, e de que essa harmonização depende de uma 'memória coletiva'. Vasconcelos (2014) faz uma analogia desta metáfora da orquestra para a arte da dança:

[...] podemos pensar em um corpo de baile de um Ballet Clássico de repertório, aonde todos os bailarinos precisam dançar em uníssono, necessitando de uma mesma gama de conhecimentos técnicos, conceituais e históricos daquela obra. Essa memória coletiva é essencial para a execução de uma obra desta magnitude e para a transmissão da mesma às gerações futuras (p. 14).

Como outros teóricos citados neste estudo, Halbwachs (2006) firma relação entre memória e identidade. Para o autor, o compartilhamento de memórias contribui para a formação de uma "comunidade de sentimentos". Por meio da memória, o grupo lança suas raízes no passado, assentando suas origens num momento distante e, muitas vezes, mítico. Essas memórias são objetivadas no espaço, conferindo materialidade e estabilidade ao modo de vida do grupo (HALBWACHS, 2006 apud RIOS, 2013).

Rios (2013, p. 11) esclarece acerca do pensamento de Halbwachs:

Para Halbwachs, o que importa é o caráter coletivo da memória, ou seja, a influência dos "quadros sociais da memória" sobre a formação das lembranças dos indivíduos. Para ele, esses quadros servem como pontos de referência que organizam as memórias dos grupos - e dos indivíduos, enquanto membros dos grupos -, conferindo estabilidade e coerência às representações coletivas. A memória contribui para a formação de identidades, e isso se dá na medida em que os grupos se constituem como "comunidades de sentimentos". A adesão dos indivíduos aos grupos e às representações coletivas ocorreria no plano afetivo. [...] Para Halbwachs, a memória tem um caráter múltiplo, na medida em que cada grupo cultiva um conjunto particular de lembranças.

Entretanto, para Pollak (1992), essa diversidade, denominada por Halbwachs de caráter múltiplo, é o que leva a memória a se tornar objeto de conflitos e disputas, pois "os grupos procuram salvaguardar suas visões sobre 0 passado, impondo-as sobre os demais" (RIOS, 2013, p. 11).

Para Halbwachs, as recordações dos indivíduos se formam a partir dos quadros sociais fornecidos pelos grupos dos quais eles participam e por sua vez, Pollak (1992) reconhece a importância das práticas individuais para a constituição, mudança e atualização das estruturas sociais. Para Polak, os indivíduos elaboram subjetivamente os acontecimentos, participam ativamente do processo de formação das memórias dos grupos e administram suas próprias lembranças em harmonia com a identidade que almejam construir para si mesmos. Ou seja, isso corrobora 
com Dubar (1997), que afirma que a "identidade nunca é dada, é sempre construída". Para o autor esta construção (processo de constituição da identidade), que ele chama de formações identitárias - pois para ele são várias as identidades que assumimos - se constitui em movimento de tensão permanente entre o que ele define de identidades virtuais, ou seja, os atos de atribuição (o que os outros indivíduos dizem que o sujeito é) e os atos de pertença (o próprio sujeito se identifica com as atribuições recebidas, aderindo às identidades atribuídas).

Dubar esclarece que a atribuição corresponde à identidade para o outro e a pertença indica a identidade para si, sendo que o movimento de tensão se caracteriza pela oposição entre o que esperam que o sujeito assuma e seja e o desejo do próprio sujeito em ser e assumir determinadas identidades. O processo de constituição identitária, segundo o autor, está na identificação ou não identificação com as atribuições que são sempre do outro, visto que esse processo só é possível no âmbito da socialização. A essência da identidade constrói-se em referência aos vínculos que conectam as pessoas umas às outras.

Baumann (2005) considera, entretanto, que não é nada fácil conceituar identidade, sendo que ela se revela como invenção e não descoberta. Para o autor identidade é um esforço, um objetivo, uma construção; é algo inconcluso, precário. O pensar sobre se ter uma identidade não ocorre enquanto se acredita em um pertencimento, mas quando se pensa em uma atividade a ser continuamente realizada. Essa ideia surge do que Baumann chama de crise do pertencimento

Souza (2014, p. 92) afirma que "segundo a concepção pós-moderna, não há mais uma identidade fixa, essencial ou permanente“. Hall (2006) nos traz a noção de identidade como um processo. Nesse contexto, Souza (2014) a partir de Hall (2006) indica que:

\footnotetext{
O sujeito cartesiano, dotado de uma identidade unificada e estável, é desintegrado e se torna fragmentado, "[...] composto não de uma única, mas de várias identidades, algumas vezes contraditória e não-resolvidas. $\mathrm{O}$ próprio processo de identificação, através do qual nos projetamos em nossas identidades culturais, tornou-se mais provisório, variável e problemático" (HALL, 2006, p. 12). Nesse panorama, "a identidade torna-se uma "celebração móvel" formada e transformada continuamente em relação às formas pelas quais somos representados ou interpelados nos sistemas culturais que nos rodeiam. (SOUZA, 2014, p.92-93)
}

Hall ainda alerta que o confronto com uma verdadeira gama de identidades culturais é traço marcante da contemporaneidade e que o fenômeno da globalização 
contribui para o deslocamento das identidades culturais desintegrando-as, homogeneizando-as e, consequentemente, enfraquecendo-as.

Hall (2006) e Pollak (1992) argumentam, conforme indicado por Souza,

sobre as identidades serem formadas sempre com relação ao outro e ao grupo. [...] Os indivíduos são constantemente postos em relação com o outro. A pós-modernidade revelou a alteridade como elemento constituinte do sujeito. O indivíduo é moldado diante da diferença, num processo de aproximação e distanciamento, por isso não é possível crer em identidades estáveis, consolidadas, fechadas. (SOUZA, 2014, p.94)

Estes autores concluem também que as identidades hoje são "processos de negociação".

O importante do exposto é que "memória e identidade podem perfeitamente ser negociadas, e não são fenômenos que devam ser compreendidos como essências de uma pessoa ou de um grupo" (POLLAK, 1992, p. 5). Sendo possível confronto entre memória individual e dos outros, portanto a memória e a identidade são valores disputados em conflitos sociais e intergrupais.

De um modo geral, existe certo consenso, entre os autores citados neste estudo, de que a identidade é uma construção social, permanentemente redefinida em uma relação dialógica com o outro, que também a memória é uma reconstrução continuamente atualizada do passado e que memória e identidade estão indissoluvelmente ligadas.

\section{SOBRE IDENTIDADE PROFISSIONAL}

O indivíduo passa por numerosos processos de socialização ao longo de sua trajetória, refletindo na sua capacidade de interagir com os outros num determinado contexto sociocultural. Este processo de socialização, segundo Dubar (1997), permite compreender a noção de identidade numa perspectiva sociológica restituída numa relação de identidade para si e identidade para o outro. O autor afirma que as identidades estão em movimento e a dinâmica de desestruturação/estruturação pode, às vezes, tomar forma de "crise de identidade".

Dubar (1997) esclarece que o processo de construção da identidade profissional deverá ser permeado pela dinâmica de mercado, pela concepção de trabalho e pela posição e status da profissão no contexto social. A socialização profissional, iniciada na formação, estimula a aquisição de comportamentos específicos, que devem ser postos em prática no exercício da profissão. Como tem, 
simultaneamente, caráter permanente e temporário, estes comportamentos modificam-se ao longo das experiências posteriores, constituindo parte da realidade do mundo de trabalho. A identidade profissional em formação, resultante do processo de formação, pode ser ratificada ou modificada ao longo do seu exercício, sob influência e pressão do contexto social e econômico, ou seja, do contexto atual de trabalho.

A identidade profissional são identidades especializadas, relacionadas a saberes específicos e a papéis vinculados à divisão social do trabalho. Contudo, não deve ser confundida com a identidade social, apesar das duas conservarem uma relação muito próxima, já que a identidade social é o "resultado a um só tempo estável e provisório, individual e coletivo, subjetivo e objetivo, biográfico e estrutural, dos diversos processos de socialização que, em conjunto, constroem os indivíduos e definem as instituições" (DUBAR, 1997, p. 136).

Identidade profissional pode ser entendida como uma construção social assinalada por diversos fatores como a nossa história de vida, as condições objetivas de trabalho e o imaginário que permeia a profissão que, ao interagirem entre si, tem como resultado uma série de representações que fazemos de nós mesmos e das funções que exercemos (LIMA, 2012).

Candau afirma que "todo grupo profissional valoriza os comportamentos apropriados e reprime os demais a fim de produzir uma memória adequada à reprodução de saberes e fazeres e à manutenção de uma identidade da profissão. A aquisição de uma identidade profissional ou, mais genericamente, de uma identidade vinculada a poderes e saberes não se reduz apenas a memorizar e dominar certas habilidades técnicas: ela se inscreve, na maior parte dos casos, nos corpos mesmos dos indivíduos" (2014, p. 118-119).

Ao construir uma representação da profissão nos resguardamos enquanto grupo profissional. Criamos uma identidade social para nós mesmos e para o coletivo, permitindo, desse modo, nos reconhecer como profissionais e desempenhar nossas atividades. Em outras palavras, são construídas imagens e significados da profissão para the dar concretude (LIMA, 2012). Essas imagens e significados, enfim, essas representações, são uma forma de conhecimento socialmente elaborada e partilhada, com um objetivo prático, e que contribui para a construção de uma realidade comum a um conjunto social (JODELET, 2001 apud LIMA, 2012). 
Para cada um de nós a identidade expressa a representação que temos de nós mesmos. Deste modo, as identidades são representações subjetivas que se constroem a partir de diferentes discursos e práticas sociais (HALL, 2006). Em diferentes períodos e espaços atribuímos inúmeros significados às nossas experiências e aquilo que somos como profissionais. Significando dizer que a construção da identidade profissional é um território de disputa permanente (LIMA, 2012). A tentativa de delinear uma identidade profissional do indivíduo pressupõe situá-lo na complexidade de um contexto social, histórico, político e cultural. Uma contextualização contemporânea de profundas mudanças que estão provocando transformações nas profissões, uma vez que a constituição de identidade tem relação com a realidade na qual se insere. Nesse sentido alguns pontos afetam a maneira como exercemos a profissão e possíveis discussões se apresentam, implicando em novos princípios estruturadores de nossa identidade profissional.

\section{ASPECTOS TEÓRICOS ACERCA DE PROFISSÃO}

Dubar (1997) afirma que antes da multiplicação das universidades no século $\mathrm{XIII}$, o trabalho era algo consagrado e todos os trabalhadores, sejam eles das artes liberais (artistas, intelectuais) ou das artes mecânicas, (artesãos, trabalhadores manuais). A separação entre artes liberais e artes mecânicas ocorre com a expansão e fortalecimento das universidades, gerando uma oposição entre profissões. A profissão passa a ser associada ao espírito, ao intelectual, ao nobre (artes liberais) e o ofício surge associado à mão, braços, prático, etc. (artes mecânicas) (ANGELIN, 2010).

Segundo Freidson (1998), "qualquer que seja a forma de definir "profissão" ela é, antes de tudo e principalmente, um tipo específico de trabalho especializado" (1998, p. 2). Algumas atividades não são reconhecidas como trabalho, algumas vezes, porque não são formalmente recompensadas, outras, porque não são realizadas em tempo integral. Em outras ocasiões são atividades pagas e realizadas em tempo integral, mas informalmente, à margem da economia oficial. Freidson esclarece que

[...] o restante desse amplo universo de trabalho é composto de ocupações e ofícios desempenhados na economia reconhecida oficialmente. É aí que encontramos as profissões, listadas como um tipo especial de ocupação nas modernas classificações oficiais. Contudo, nenhuma teorização sobre profissões (sem falar de outros tipos de trabalho) pode tratar do trabalho 
reconhecido oficialmente sem considerar também aquele não reconhecido, na economia informal, no mínimo porque muitas profissões tiveram suas origens na economia informal e só depois se tornaram reconhecidas oficialmente (1998, p. 2).

Para Freidson, "as profissões, enquanto ocupações reconhecidas oficialmente, se distinguem em virtude de sua posição relativamente elevada nas classificações da força de trabalho" (1998, p. 2). Segundo ele, "profissionais são aquelas pessoas que criam, expõem e aplicam aos assuntos humanos o discurso de disciplinas, campos, corpos demarcados de conhecimento e qualificação. Esse é seu trabalho, que não pode ser desempenhado sem instituições que Ihes garantam apoio econômico, poder e organização" (1998, p. 9).

Quando se fala do artista como trabalhador, Kronemberger (2016, p. 12) comenta que as profissões artísticas possuem diversas particularidades, das quais o autor destaca duas principais:

[...] o status do artista não é protegido por títulos ou certificados educacionais (dificuldade de definição dos critérios de entrada nas posições ofertadas no mercado - Quais são os critérios sociais legítimos para se tornar artista?); e a relação particular com o mercado (demanda complexa e instável das atividades e produtos artísticos).

Essas singularidades, para Kronemberger (2016) trazem um problema teórico fundamental - o de definição do termo profissão. Para a autora, muitas profissões, principalmente as liberais, possuem um processo de profissionalização no qual suas atividades de formação se ligam às universidades, onde a certificação acadêmica autoriza a prática da profissão. Desta forma, os títulos de formação formal se constituem em um traço constitutivo da definição das profissões. Outro aspecto característico nas definições da noção de profissão é a sua vinculação à atividade remunerada. Entretanto, especificidades encontradas em profissões artísticas, problematizam as noções usuais de profissão e de trabalho, que tomem como centrais as credenciais acadêmicas e a relação entre atividade produtiva e mercado, sobretudo no que se refere à remuneração.

Conforme Kronemberger (2016), produtos culturais de grande alcance, competências exigidas dos artistas, inspiração, formação extrema, são critérios que justificam essas atividades como profissões. Entretanto...

[...] as profissões artísticas colocam um problema sociológico fundamental de como construir um conceito geral de profissão que leve em conta atividades como estas e não se baseie em critérios apenas econômicos e de certificações educacionais formais. Ou seja, este é um caso em que objetivamente são os critérios sociais os principais definidores da posição social desse grupo (KRONEMBERGER, 2016, p. 12). 
De acordo com Kronemberger (2016) acerca do contexto social deste grupo, Freidson, Chamboredon e Menger (1986), afirmam que, para considerar a atividade artística uma profissão, devemos ir além de uma definição que leve em conta apenas critérios econômicos. Freidson, Chamboredon e Menger (1986) afirmam que esta definição esteve por muito tempo dominante, a ponto de nos cegar sobre o alcance teórico da prática contemporânea das artes. Para estes autores, devemos considerar a profissão como "um empreendimento humano organizado visando ao cumprimento de tarefas especializadas às quais se reconhece um valor social" ( $p$. 440). Trata-se do exercício de uma "competência especializada dentro da divisão do trabalho" (p. 440) ou de uma função social.

Seja como for, Dubar (1997) afirma que o processo de construção da identidade profissional tem seu inicio mediante confrontação com as relações, o ambiente e o mercado de trabalho.

\subsection{ARTE E PROFISSÃO}

Os teóricos Freidson, Chamboredon e Menger (1986) afirmam que poucos artistas sobrevivem de sua arte. Geralmente são obrigados a exercer outras atividades econômicas para garantirem seu sustento, diferentemente de profissionais de outras áreas, como médicos, engenheiros, advogados. Além disso, Menger (2005 apud ARRUDA, 2010, p. 57) afirma que:

[...] o mercado capitalista, incerto e instável, utiliza o trabalho do artista como modelo de trabalho flexível, uma vez que o artista--trabalhador dificilmente consegue se manter apenas com o resultado de sua criação, precisando dedicar-se a formas multifacetadas de trabalho: o auto-emprego, o freelancing, e as diversas formas atípicas de trabalho - trabalho intermitente, trabalho a tempo parcial, multi-assalariado.

Para Freidson, Chamboredon e Menger (1986) as profissões artísticas são as mais ambíguas e constituem um desafio à análise teórica das profissões e do trabalho. De acordo com estes autores, Cerqueira (2015) esclarece que a dificuldade de se entender o artista como trabalhadores deriva da ideologia romântica da criação como algo fora do mundo, tornando as análises com tendências a "privilegiar a obra do artista enquanto criação estética, em prejuízo do processo de trabalho que a elaborou" (p. 2). Existe uma percepção profissional do artista fundamentada numa visão bastante idealizada da vocação, escondendo aspectos reais de uma carreira. 
A arte é considerada inspiração pura, irracional, somente suscetível de revelação e não de compreensão, interior, gratuita, transcendente, mágica e iluminada. Contudo, Cerqueira (2015, p. 2) esclarece:

Contrariando as compreensões que encerram as explicações do trabalho artístico em palavras como talento natural, dom, vocação e genialidade, observa-se que o trabalho artístico é (também) um processo consciente e racional, ao fim do qual resulta uma obra como realidade dominada e não de modo algum - um estado de pura inspiração. O ofício do artista requer um longo processo de formação profissional. Todo ensaio, todo espetáculo significa, ao mesmo tempo, trabalho.

Diante deste contexto torna-se "importante um esforço de análise que compreenda a própria realidade desse campo em suas dinâmicas, contradições, estratégias de envolvimento e dificuldades de identidade e organização" (CERQUEIRA, 2015, p. 2).

Segundo Segnini (2006) os artistas, frequentemente, são descritos de forma preconceituosa e plena de estereótipos, com uma visão equivocada referente ao trabalho de criação como sendo um processo individual e solitário, indiferente a opinião do público e ao sucesso. Para a autora trata-se de uma visão distorcida do trabalho artístico.

Em suas pesquisas Segnini (2006) identifica que a escolha da profissão para os artistas de espetáculo é, geralmente, uma escolha própria, pautada na paixão em exercê-la. Normalmente, antes de se tornarem profissionais, a arte escolhida já era um hobbie, uma atividade de lazer na vida do sujeito. A autora também relata acerca de suas investigações que esses trabalhadores artistas - músicos e bailarinos estão submetidos à constante incerteza face à garantia do trabalho. É permanente, para estes artistas, a procura por trabalho, uma vez que é comum dependerem de projetos artísticos que, quando contemplados, são por tempo determinado. Importante lembrar que a remuneração nesta área é mediante a execução do espetáculo, muitas vezes não levando em consideração todo o preparo dos artistas para a performance. Contudo, mesmo desempregados, os profissionais artistas necessitam se manterem sempre prontos para o trabalho, mesmo sem nenhuma programação estabelecida, pois as oportunidades podem aparecer a qualquer momento. No caso de bailarinos, esclarece Segnini (2006) é preciso manter o corpo preparado diariamente e os músicos necessitam realizar um estudo diário com seus instrumentos musicais. Os artistas são trabalhadores que trabalham diariamente, sem ter a garantia do espetáculo ao vivo, ou seja, sem garantias de remuneração. 
Por excelência, o trabalho artístico é considerado flexível tanto em termos de conteúdo, locais, horários e contratos de trabalho. A instabilidade na condição de trabalho e na carreira do artista é reconhecida historicamente em vários países, incluindo o Brasil.

Ao analisar a profissionalização dos músicos de Porto Alegre, a pesquisadora Julia da Rosa Simões (2016) aborda em sua tese alguns pontos interessantes que podem ser considerados acerca dos profissionais das artes (p. 1314):

Muito ligada ao lazer e à arte, a música parece principalmente uma ocupação prazerosa, desvinculada de questões pragmáticas. É comum não se pensar na dimensão profissional da atividade ao se considerar a atuação dos músicos no contexto histórico brasileiro [...] A arte, e também a música, é muitas vezes vista como o inverso da vida econômica, lembrou o sociólogo Craig Calhoun, interessado por esse "mundo" tão contraditório. Visto não ser muito conhecida a labuta diária dos instrumentistas pela subsistência, dentro ou fora de seus ambientes performáticos (palcos, salas de aulas etc.), [...] uma "profissão difícil" ou "mais obscura" - para citar estudos recentes sobre história das profissões artísticas.

Simões apresenta alguns pontos importantes para que se compreendam as ocupações artísticas (2016, p. 17):

[...] é preciso apontar a necessidade de ampliar-se o conceito de profissionalização para categorias afastadas das definições ideal-típicas, como é o caso das ocupações artísticas, para que também se possa estudar as formas de auto-organização que tais categorias colocam em prática, bem como sua capacidade de erigir e fazer respeitar barreiras para a entrada em seu campo de atividade, ou suas estratégias no que concerne ao mercado, à concorrência e à liberdade profissional.

Pensar em artistas - sejam eles músicos, bailarinos, atores - como profissionais envolve o conhecimento de certas especificidades destes ofícios que, conforme Simões (2016), devem levar em consideração que são diversas as competências e qualidades exigidas pelo trabalho não-alienado desempenhado pelo artista. Para a autora:

Este se movimenta entre dois mundos, sendo artista - criando, interpretando -, mas também trabalhador - vendendo sua força de trabalho no mercado. Sua atividade não pode ser definida como mero lazer, apesar de muitas vezes seguidamente prazerosa e muitas vezes sem fins lucrativos, mas também escapa à categorização usual de trabalho remunerado, pois nem sempre o critério econômico é suficiente para diferenciar o amador do profissional. Aliar arte e profissão parece constituir um desafio e uma ambiguidade, tanto para os analistas da matéria quanto para seus protagonistas (SIMÕES, 2016, p. 18).

Baseada em Frederickson e Rooney (1990), Simões (2016, p. 19) considera a música como uma semiprofissão, apresentando três motivos básicos: 
1) músicos dominam um corpo de conhecimento especializado e técnicas, mas não são exigidos a completar um treinamento padronizado; 2) eles fracassaram em assegurar um monopólio legal sobre o campo da performance através da exigência de teste e licenciamento de graduados; e 3) eles têm autonomia limitada: precisam rigorosamente coordenar seu tocar sob a direção de um regente, e a função de sua performance é muitas vezes controlada pelo cliente.

A música seria uma semiprofissão basicamente por possuir características tanto de ofício quanto de profissão. Frederickson, Rooney (1990) e Simões (2016) consideram, portanto, que "o sucesso em música poderia ser medido através de habilidades facilmente observáveis, não através de certificação de conhecimento, conforme atestado pelo fato de um diploma não ser pré-requisito para a entrada em orquestras. Os autores concluem que em sua ênfase em habilidades observáveis, a música revela sua essencial orientação de ofício: fazer é mais importante do que saber" (p. 19).

Analisando as considerações e conclusões apresentadas por Frederickson, Rooney e Simões, claramente reconhecemos situação semelhante com profissionais bailarinos. Os bailarinos, como os músicos, têm sua formação...

[...] baseada num aprendizado de artífice/artesão, ou seja, na "habilidade manifesta de copiar a performance do professor: análises críticas das tradições do ofício são desencorajadas, e consentimento mútuo dos procedimentos é a base na qual uma lealdade é estabelecida (SIMÕES, 2016, p. 19).

Entretanto esse não é o caso no ensino formal de dança em que, como na música, se procura colocar o seu estudo mais próximo das demais áreas acadêmicas, mas em linhas gerais, segundo Simões (2016), o ensino musical continua dependendo de observação direta e trabalho sob a batuta de um mestre, situação semelhante na dança.

Simões (2016) revela outra situação acerca dos profissionais músicos bastante semelhante aos profissionais bailarinos: o perfil enquanto empreendedores dedicados a carreiras freelance, ou enquanto trabalhadores independentes de patrões ou instituições. A autora menciona que o "músico seguidamente precisou dividir-se entre várias atividades: instrumentista, compositor, arranjador e, acima de tudo, professor. Em todas, necessitou ser oportunista, no sentido de que desenvolveu a habilidade de perceber oportunidades e tirar vantagem delas" (p. 23).

Em concordância com Simões (2016), Cerqueira (2015, p. 2) afirma que nas análises do trabalho artístico... 
[...] é possível identificar tanto as seduções de um mercado de trabalho não tradicional (valorização da autonomia, da responsabilidade, da criatividade) quanto às ameaças da efemeridade dos empregos (banalização da atipia salarial e respectivos riscos) e da intensidade da concorrência num contexto de grande fragmentação do trabalho e de grande variabilidade das competências exigidas. Diante disso, o próprio indivíduo é chamado a comportar-se como empresário da sua própria carreira, portfólio worker, a custo de uma forte individualização do seu sistema pessoal de atividade.

A autora esclarece que seus estudos acerca do trabalho artístico, baseados em autores como Menger (2005), Segnini (2006) e Benhamou (2007), permitem afirmar que o trabalho artístico é caracterizado pela imagem de flexibilidade e inserido em contexto de auto-emprego, freelancing e diversas formas atípicas de trabalho (intermitência, tempo parcial, multi-assalariado).

\subsection{O PROFISSIONAL DA DANÇA}

No universo da dança, parece importante mencionar acerca do fato de que a dedicação à dança está atrelada ao conceito de vocação, sendo este mais forte do que o conceito de trabalho ou ocupação, e sendo talvez também superior ao conceito de ofício e profissão, segundo Wainwright e Turner (2006 apud NACHT, 2009). A ideia de vocação, normalmente associada à inclinação religiosa, está também relacionada ao sacrifício e sublimação, e, geralmente, aquele que é movido pela vocação tem uma personalidade que é colocada à prova pelas incontáveis dificuldades que se apresentam pelo caminho e o pouco reconhecimento pelo seu esforço (WEBER, 2000). Normalmente o sacrifício e a devoção fazem parte da rotina dura de treinamento e ensaio do bailarino, além da contínua presença da dor e de possíveis lesões. O risco de lesão significa também o risco de parar de dançar representando grande impacto em sua identidade (WAINWRIGHT; TURNER, 2006 apud NACHT, 2009).

O que se estabelece para este profissional, certamente, é que sua ferramenta de trabalho é, sem dúvidas, seu próprio corpo. E este tem de estar preparado tecnicamente, além de apresentar uma imagem exigida pelo estilo de dança - longilínea e magra, para o ballet clássico, por exemplo - devendo ser saudável e vigoroso.

Outra característica fortemente encontrada neste meio profissional é a competição. Este parece ser atributo estrutural da experiência de vida e de trabalho de bailarinos (as). 
Uma espécie de ética do "eu por mim mesmo/a" é o que determina o funcionamento do mercado de trabalho destes. Cada aspirante precisa ser aceito e ingressar inicialmente numa companhia por uma espécie de audição determinada. Depois é cotidianamente testado em aulas, ensaios que selecionam quem vai dançar os melhores papéis, os papéis secundários, e, até mesmo, quem não vai dançar. Todos os dias, portanto, uma competição. (AGOSTINI, 2010, p. 5).

Menger (2005) comenta que a organização do trabalho em dança impõe flexibilidade elevada ao trabalhador artista. Para manutenção das organizações do espetáculo ao vivo, existe uma necessidade de recrutamento rápido por meio de redes de conhecimento, audições (identificação dos melhores artistas para cada espetáculo) e de acordo com diferentes possibilidades de remuneração/cachês. Esta condição reflete no profissional artista. Segnini e Lancman (2011, p. 43) explicam:

O processo de construção de um espetáculo exige dupla dimensão dos
bailarinos: trabalho individual e coletivo. No trabalho individual é observado
o desenvolvimento da técnica; o conhecimento do próprio corpo, pesquisa
sobre movimento, obtenção de repertório de movimento por meio da
investigação individual e manutenção dos requisitos em termos biológicos.
Os bailarinos e bailarinas estão em constante movimento, uma vez que o
instrumento de trabalho é o corpo, é preciso mantê-lo sempre pronto para o
trabalho. [...] Assim como é de extrema necessidade o trabalho realizado
coletivamente sob as orientações do coreógrafo, com o objetivo de se
aprender o movimento de determinada coreografia (ensaios).

Diante deste contexto Rannou e Roharik (apud SEGNINI; LANCMAN, 2011) afirmam que a carreira do bailarino pode ser resumida em quatro grandes etapas:

[...] a primeira, encantamento com a atividade; muito comumente, engajamse precocemente na profissão por meio de um ciclo de formação informal especializada, escolas de dança, por exemplo. O segundo momento é decisivo na carreira do bailarino, no qual o profissional buscará se colocar no mercado e se estabilizar enquanto artista da dança. Nesta trajetória, o terceiro período é caracterizado pela maturidade e reconhecimento profissional. No entanto, o quarto momento tende a ser marcado por complicações profissionais relacionadas, sobretudo com o corpo. Anunciando assim a saída do palco (Rannou; Roharik, 2006 apud Segnini; Lancman, 2011, p. 44).

Segnini e Lancman (2011) concluem que "a relação entre o amadurecimento profissional e a necessidade de um corpo jovem expressa um potencial conflito permanente na profissão", pois...

O amadurecimento profissional é um prelúdio do fim da atividade. Desta forma, é observada uma relação ambígua: quanto mais o profissional amadurece e se torna mais cônscio de suas habilidades e fragilidades, também se depara com a proximidade de ter que se retirar da cena em razão de um corpo que se fragiliza biologicamente e é menos valorizado no mundo da dança. A preocupação com o futuro profissional é frequente entre os bailarinos (SEGNINI; LANCMAN, 2011, p. 44).

Em um estudo de caso realizado pela pesquisadora Neves (2013) com o Cisne Negro Cia. de Dança de São Paulo, SP, a profissão de bailarino(a) foi 
considerada um ofício pouco reconhecido como profissão e que implica muitos sacrifícios. Sendo uma carreira bastante concorrida e curta, por conta das restrições impostas pelo envelhecimento do corpo, e cujas recompensas materiais não são expressivas e sendo limitados os espaços que garantem estabilidade de emprego.

\section{COMENTÁRIOS ESPECULATIVOS}

As considerações levantadas acerca de identidade têm a finalidade de contextualização para estudo que, se presume, deverá apontar para configuração de alguns perfis identitários que estão se formando, sobretudo, com a diversificação que se apresenta na formação e atuação do bailarino nesta primeira década do sec. XXI.

A formação profissional do bailarino, neste seu novo contexto de formalidade (acadêmico), assume as responsabilidades e papéis, que vão além da transmissão e construção de conhecimentos teóricos e práticos, perfazendo uma responsabilidade maior na construção e no desenvolvimento de identidades, desde a educação básica a educação superior, além do desenvolvimento de uma consciência crítica e emancipatória do bailarino.

Espera-se com este levantamento fundamentar uma investigação para tentar delinear uma imagem e identidade a partir da formação e atuação do profissional bailarino. A intenção não é chegar a uma conclusão final, uma vez que se considera o caráter da transitoriedade das configurações identitárias e das imagens do bailarino. 


\title{
THE DANCER AND HIS PROFESSIONAL CONTEXT: A STUDY ABOUT PROFESSIONAL IDENTITY
}

\begin{abstract}
:
The purpose of this study in the area of Social Memory is to discuss the concepts of identity, profession and art as work, with emphasis on the professional dancer. The term identity can only be understood by an interdisciplinary approach, in the crisscross of areas such as Sociology, Psychology, Anthropology and History. In this context, professional identity is understood as a continuous process linked to personal identity, also linked to the bonds and sense of belonging to a specific category or social group. The considerations raised about identity, profession, occupation, job and work, have the goal of contextualizing the main study that is trying to delineate an image and identity of the professional dancer, as well as to instigate further research in this subject.
\end{abstract}

Keywords: Identity. Professional Dancer. Dance

\section{EL BAILARÍN Y SU CONTEXTO PROFESIONAL: UN ESTUDIO ACERCA DE LA IDENTIDAD PROFESIONAL}

\section{Resumen:}

La propuesta de esta investigación en el área de la Memoria Social tiene como objetivo discutir sobre los conceptos de identidad, profesión y arte como trabajo, dando énfasis al profesional bailarín. El concepto de identidad no puede ser comprendido sino por vías interdisciplinares, en el entrecruzamiento de áreas como Sociología, Psicología, Antropología e Historia. En este contexto, se comprende identidad profesional como un proceso continuo que se vincula a la identidad personal, igualmente ligada a los vínculos y sentimientos de pertenencia a una determinada categoría o grupo social. Las consideraciones planteadas, acerca de identidad, profesión, oficio, ocupación y trabajo, tienen la finalidad de contextualización para el estudio que está tratando de delinear una imagen e identidad del profesional bailarín, así como instigar nuevas investigaciones en esta temática.

Palabras clave: Identidad. Profesional Bailarín. Danza. 


\section{REFERÊNCIAS}

AGOSTINI, Bárbara Raquel. Como as bailarinas clássicas percebem seus corpos sob a influência da cultura corporal da dança: um estudo que aborda corpo e subjetividade. In: CONGRESSO NORDESTE DE CIÊNCIAS DO ESPORTE, 3., 2010, Ceará. Anais... Ceará: Universidade Federal do Ceará, 2010. Disponível em: < http://congressos.cbce.org.br/index.php/conece/3conece/paper/viewFile/2236/976> Acesso em: 20 jul. 2016.

ANGELIN, Paulo Eduardo. Profissionalismo e profissão: teorias sociológicas e o processo de profissionalização no Brasil. REDD - Revista Espaço de Diálogo e Desconexão, Araraquara, v. 3, n. 1, jul/dez. 2010.

ARRUDA, Carmen Lúcia Rodrigues. Produção artística na universidade: relações de trabalho do professor-artista na UNICAMP. Comunicações, Piracicaba, v. 17, n. 2, p. 51-64, jul./dez. 2010.

BAUMANN, Zygmunt. Identidade: entrevista a Benedetto Vecchi. Rio de Janeiro: Jorge Zahar, 2005.

BENHAMOU, Françoise. A economia da cultura. São Paulo: Ateliê Editorial, 2007.

CANDAU, Joel. Memória e identidade. São Paulo: Contexto, 2014.

CERQUEIRA, Amanda P. Coutinho de. O artista como trabalhador. In: COLÓQUIO INTERNACIONAL MARX E ENGELS, 8., 2015, Campinas. Anais... Campinas: UNICAMP, 2015. Disponível em: < https://www.ifch.unicamp.br/formulario cemarx/selecao/2015/ > Acesso em: 28 jun. 2017.

DUBAR, Claude. A socialização: construção das identidades sociais e profissionais. Tradução. Anette Pierrette R. Botelho e Estela Pinto R. Lamas. Portugal: Porto, 1997.

FREDERICKSON, Jon; ROONEY, James F. How the Music Occupation Failed to Become a Profession. International Review of the Aesthetics and Sociology of Music, v. 21, n. 2, dez. 1990.

FREIDSON, Eliot. Renascimento do profissionalismo. São Paulo: EDUSP, 1998. 
FREIDSON, Eliot; CHAMBOREDON, Jean-Claude; MENGER, Pierre-Michel. Les professions artistiques comme défi à l'analyse sociologique. Revue française de sociologie, v. 27, n. 27-3, p. 431-443, 1986.

HALBWACHS, Maurice. Les cadres sociaux de la mémoire. Paris: Albin Michel, 1994.

A memória coletiva. São Paulo: Centauro, 2006.

HALL, Stuart. A identidade cultural na pós-modernidade. Rio de Janeiro: DP\&A, 2006.

JODELET, Denise. Representações sociais: um domínio em expansão. In: (org.). As representações sociais. Rio de Janeiro: EDUERJ, 2001. p. 18-66.

KRONEMBERGER, Gabriela Almeida. Profissão e performance: um estudo de caso sobre músicos de orquestra. Revista Música Hodie, Goiânia, v.16, n. 2, p. 10-24, 2016.

LIMA, Maria do Socorro Carneiro de. Imagem e identidade: estudo sobre o professor universitário. 462f., 2012. Tese (Doutorado em Educação) - Universidade de Lisboa, Lisboa, 2012.

MENGER, Pierre-Michel. Retrato do artista enquanto trabalhador: metamorfoses do capitalismo. Lisboa: Roma, 2005.

NACHT, Antonia Kjellerup. A profissão de bailarino na cidade do Rio de Janeiro: mercado de trabalho, relações profissionais, decisões de carreira e identidade profissional. 148f. 2009. Dissertação (Mestrado em Administração) - Pontifícia Universidade Católica do Rio de Janeiro, Rio de Janeiro, 2009. Rio de Janeiro: PUCRJ, 2009.

NEVES, Juliana Cunha Lima. Bailarinas e bailarinos: uma etnografia da dança como profissão. Cadernos Pagu, n.41, p. 201-238, jul./dez. 2013.

POLLAK, Michael. Memória e identidade social. Estudos Históricos, Rio de Janeiro, v. 5, n. 10, p. 200-212, 1992. Transcrição e tradução de Monique Augras. 
RANNOU, Janine; ROHARIK, lonela. Les danseurs: un métier d'engagement. Paris: La Documentation Française, 2006.

RIOS, Fábio Daniel. Memória coletiva e lembranças individuais. INTRATEXTOS, Rio de Janeiro, v. 5, n. 1, p. 1-22, 2013.

SEGNINI, Marina Petrilli. Prazer e sofrimento no trabalho artístico. In: CONGRESSO INTERNACIONAL DE PSICOPATOLOGIA FUNDAMENTAL, 2., 2006, Pará. Anais: trabalhos completos. Pará: Universidade Federal do Pará, 2006. Disponível em: < http://www.psicopatologiafundamental.org/uploads/files/ii congresso internacional/te mas livres/ii con. prazer e sofrimento no trabalho artistico tl.pdf > Acesso em: 28 jun. 2017.

SEGNINI, Marina Petrilli; LANCMAN, Selma. Sofrimento psíquico do bailarino: um olhar da psicodinâmica do trabalho. Laboreal, v. 7, n. 1, p. 42-55, 2011.

SIMÕES, Julia da Rosa. Na pauta da lei: trabalho, organização sindical e luta por direitos entre músicos porto-alegrenses (1934-1963). 224f. 2016. Tese (Doutorado em História) - Universidade Federal do Rio Grande do Sul, 2016. Porto Alegre: UFRGS, 2016.

SOUZA, Mariana Jantsch. A memória como matéria prima para uma identidade: apontamentos teóricos acerca das noções de memória e identidade. Revista Graphos, v. 16, n. 1, p. 91-117, 2014.

VASCONCELOS, Liana. Memória da dança: importância, registro, preservação e legado. 60f. 2014. Monografia (Graduação em Produção Cultural) - Universidade Federal Fluminense, 2014. Niterói: Universidade Federal Fluminense, 2014.

WAINWRIGHT, Steven P.; TURNER, Bryan S. Just crumbling to bits? An exploration of the body, ageing, injury and career in classical ballet dancers. Sociology, Londres, v. 40, n. 2, p. 237-255, 2006.

WEBER, Max. Ciência e política: duas vocações. São Paulo: Cultrix, 2000. 